\title{
Explaining Life: Microorganisms in Science Museums
}

\author{
Author(s): Jordi Urmeneta and Alícia Duró
}

Source: The American Biology Teacher, 73(5):265-269. 2011.

Published By: National Association of Biology Teachers

URL: http://www.bioone.org/doi/full/10.1525/abt.2011.73.5.4

BioOne (www.bioone.org) is an electronic aggregator of bioscience research content, and the online home to over 160 journals and books published by not-for-profit societies, associations, museums, institutions, and presses.

Your use of this PDF, the BioOne Web site, and all posted and associated content indicates your acceptance of BioOne's Terms of Use, available at www.bioone.org/page/terms of use.

Usage of BioOne content is strictly limited to personal, educational, and non-commercial use. Commercial inquiries or rights and permissions requests should be directed to the individual publisher as copyright holder.

BioOne sees sustainable scholarly publishing as an inherently collaborative enterprise connecting authors, nonprofit publishers, academic institutions, research libraries, and research funders in the common goal of maximizing access to critical research. 


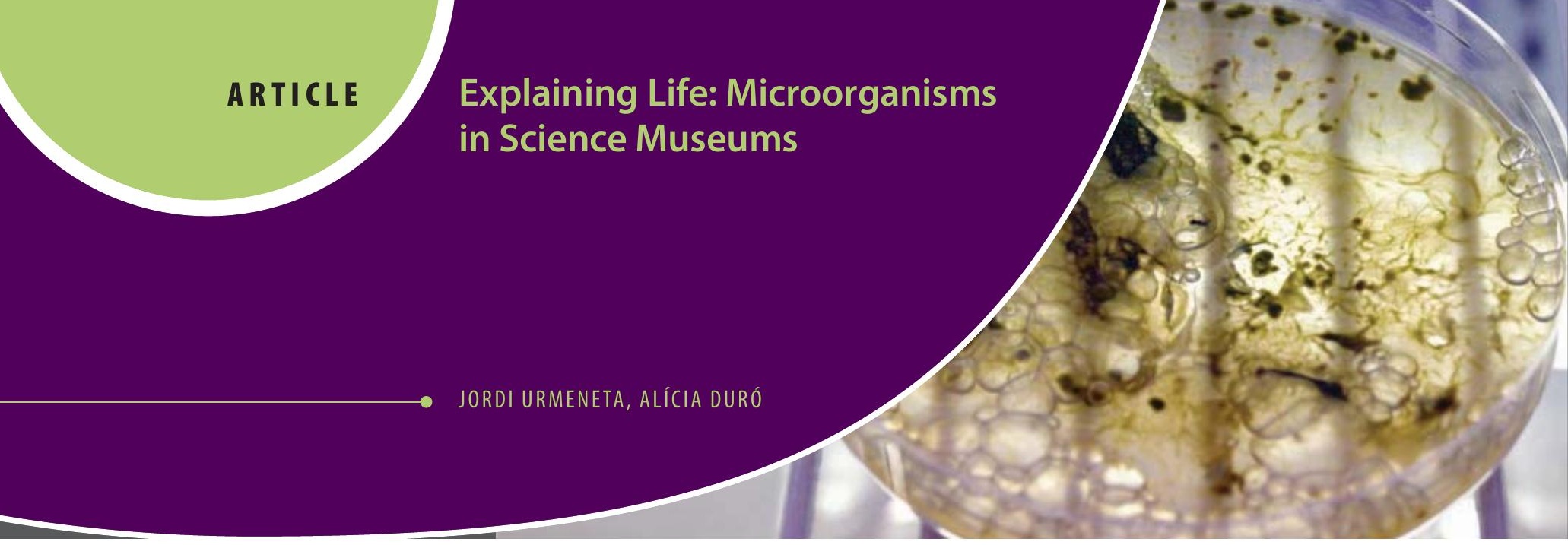

\section{Abstract}

Microorganisms were first described by van Leeuwenhoek in the 17th century. Later, Pasteur and Koch related them to diseases. Since then, the scientific community has striven to extend awareness of the many functions of microorganisms. Science museums provide an excellent setting in which to disseminate such knowledge, but the presentation of living microorganisms is a challenge. We describe an approach to the exhibition of living microorganisms pursued in a science museum in Barcelona (CosmoCaixa Barcelona). In two exhibits, the museum shows photosynthesis in cyanobacteria and Winogradsky columns, which provide an example of living microbial ecosystems.
Frank Oppenheimer founded the Exploratorium. Housed within the walls of San Francisco's Palace of Fine Arts, this museum excelled at popularizing science, mainly through hands-on exhibits. The Exploratorium and the Ontario Science Center (also founded in 1969) were pioneering initiatives in spreading scientific principles through interactive exhibits (Oppenheimer, 1968). The Palais de la Découverte and the Exploratorium currently also have exhibits and workshops involving living organisms (small mammals, fish, insects, and marine invertebrates).

Opened 30 years ago and sponsored by the Fundació "la Caixa," the Barcelona Science Museum (CosmoCaixa Barcelona) was the first

Key Words: Microorganisms; science museums;

Winogradsky columns; microbial ecosystems; oxygenic photosynthesis; cyanobacteria.

Science museums provide an excellent setting for the dissemination of knowledge. The value of teaching science in these informal contexts is considerable (Lucas, 1983; Hofstein \& Rosenfeld, 1996; Rennie \& McClafferty, 1996). One of the main merits of exhibitions is that they are designed to motivate visitors to learn about and take an interest in different aspects of science (Salmi, 2003; Pedretti, 2004; Guisasola \& Morentin, 2007). Furthermore, science museums offer parents a first-rate opportunity to share the learning experience with their children by inviting them to participate in interactive exhibits (Benlloch \& Williams, 1998).

The idea of hands-on science centers came about with the opening of the Palais de la Découverte in Paris in 1937. Jean Perrin (Nobel Prize in Physics, 1926) was responsible for the development of this interactive science museum from 1932 to 1933 . He sought to highlight the impact of science on civilization and make it more understandable for the general public. Thus, the Palais de la Découverte was the first museum to present science to everyone: "Science en train de se faire" (Maury, 1994). This museum organized science workshops in which visitors participated in experiments, thereby promoting scientific thought and the appreciation of the role of science in our daily lives. In 1969, the noted physicist and teacher interactive museum to be built in Spain. The first exhibition hall devoted to biology was The Living Planet, which was opened in 1989 Visitors observed living animals and plants and could also perform experiments themselves. Since then, biology has taken on a greater role in the museum. In September 2004, an extensive enlargement and reconstruction of the premises was completed. The new building now boasts $50,000 \mathrm{~m}^{2}$, which is four times the space in the previous building, in which the exhibits are designed for a wide range of audiences. CosmoCaixa Barcelona, with an interdisciplinary approach and an innovative museography, is now one of the most modern museums of its kind in Europe.

The permanent exhibition of CosmoCaixa Barcelona, the Room of Matter, is divided into four sections. While passing through the 49 installations in this room, visitors journey through the origin of life, its evolution, and the strategies adopted to adapt to unfolding events. In fact, these strategies have been developed because life has emerged in a highly dynamic medium. Occupying $\sim 1300 \mathrm{~m}^{2}$, the Living Matter section is divided into five parts: Evolution, Complexity, Anticipation, Action, and Uncertainty. Visitors then pass through exhibits dealing with the basic processes and structures of life, such as The First Metabolisms, Photosynthesis, The World of the Cell, and The Membrane. Furthermore, they can observe spectacular images of a diversity of living microorganisms through microscopes.

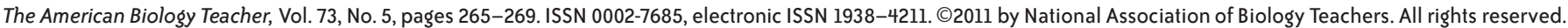

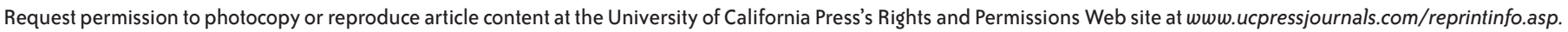
DOI: 10.1525/abt.2011.73.5.4 


\section{Knowledge about Microorganisms}

Antonie van Leeuwenhoek (1632-1723) was the first person to describe bacteria and other microorganisms. The generic name he gave to these organisms was "animalcule." Research into microorganisms brought about the invention and evolution of microscopes. Indeed, Leeuwenhoek felt a strong curiosity for animalcules that live in water, and to satisfy his quest for knowledge, he built and improved simple but brilliant microscopes (Stanier, 1951; Lechevalier \& Solotorovsky, 1974). At that time, the study of animalcules was difficult; however, more difficult still was the task of explaining these phenomena to a nonscientific public. The works of Pasteur and Koch demonstrated the importance of microorganisms in our daily life as causal agents of diseases and as the organisms responsible for the fermentation of some foods. From that moment, the development of microbiology focused on the study of infectious diseases. Consequently, the general public considered microorganisms malefic and therefore deemed it necessary to eradicate them. At present, microbiologists attempt to change this perception and to teach the public that these microbes perform other activities that are crucial for ecosystems and for the maintenance of life on our planet.

Science museums have always had a special interest in exhibiting living organisms. This has been accomplished relatively easily in the case of "large" organisms, such as animals and plants; however, microorganisms present a much greater challenge. Microorganisms, by definition, are tiny (microscopes are necessary for their observation), and the intrinsic difficulty of their manipulation and maintenance accounts for their absence in science museums until relatively recently. This absence was also paralleled by ignorance of these organisms on the part of most people. In schools, biology textbooks provide much information about organisms erroneously classified as "higher" life forms, but little is explained about the vital contribution of microorganisms to the history of the life on our planet. Recent years have brought about a recognition of the need to teach schoolchildren about these minute but critical life forms. A reflection of this new perspective is the inclusion of microorganisms in workshops and exhibits organized by science museums. At the beginning of 2003, the Exploratorium opened a new permanent exhibition that shows microorganisms of fresh water, and also fungi and bacteria.

One of the most innovative contributions of the Living Matter section at CosmoCaixa Barcelona is the exhibition on living bacteria. In the Photosynthesis exhibit, visitors can contemplate several cultures of oxygenic phototrophic bacteria in plastic Petri dishes. The photosynthetic activity of cyanobacteria is demonstrated by the production of oxygen bubbles. In the First Metabolisms exhibit, living microorganisms are presented in two glass Winogradsky columns. One shows a microbial community from an anaerobic lake from the Archaean Eon, and the other shows a community from a current aerobic lake. Visitors can contemplate these communities as true smallscale representations of ecosystems and see how they evolve. This exhibit was made possible thanks to interdisciplinary collaboration between artists and scientists.

\section{O A Vital Biological Process: Photosynthesis}

One of the most important biological processes on Earth is photosynthesis - the conversion of the energy in sunlight into chemical energy in the form of ATP. However, it must be remembered that, in addition to a source of energy, all organisms require both a source of reducing power and carbon for biosynthesis.
It is erroneous to associate the process of photosynthesis only with plants. This metabolism was already being performed by several groups of prokaryotic microorganisms more than 3000 million years ago, well before the appearance of plants.

The first photosynthetic organisms worked with only one photosystem, known as photosystem I (PSI). Current phototrophic bacteria, which resemble the first photosynthesizers, have only this photosystem. PSI captures energy from sunlight and transforms it into ATP. Most phototrophic organisms are autotrophic - that is, they have the capacity to fix $\mathrm{CO}_{2}$. They obtain reducing power mainly from sulfides (purple and green sulfur phototrophic bacteria) or from organic compounds (purple and green nonsulfur phototrophic bacteria). Given that oxygen is not produced during this type of photosynthesis, the process has been named anoxygenic photosynthesis.

The concentration of sources of reducing power used by phototrophs was progressively diminished. Sulfides and organic matter were consumed rapidly by the first bacteria while hydrogen was released. Approximately 3000 million years ago, in response to this new challenge to the maintenance of life, a handful of new phototrophic microorganisms, the cyanobacteria, emerged. These were characterized by the presence of an additional photosystem (PSII), which allowed the capture of more energy. This higher amount of accumulated energy allowed the water molecule to be split, thus producing hydrogen or reducing power. Another part of the molecule was not used and was released as gaseous oxygen. For this reason, the process is referred to as oxygenic photosynthesis.

Given that water is the main source of hydrogen on Earth, cyanobacteria developed quickly. The large amounts of oxygen produced by the photosynthetic activity of these bacteria did not enter the atmosphere immediately but remained trapped in sediment, where the oxygen oxidized the large amounts of sulfur, iron, and carbon compounds present. When all these compounds had been completely oxidized, atmospheric oxygen rapidly increased. Approximately 2000 million years ago, all the deposits of iron and other metals had been oxidized. Fossil findings demonstrate that about 2600 million years ago the atmosphere became an oxidizer, marking the beginning of the Proterozoic Eon.

The great expansion of microbial mats, formed mainly by cyanobacteria, caused a rapid increase in atmospheric oxygen. This development led to an ecological catastrophe at the planetary level. Oxygen is a highly reactive gas that captures electrons and forms free radicals that attack and destroy organic molecules. Many microorganisms died; others moved to zones with lower concentrations of oxygen; and others began to develop strategies to survive under these new conditions. The adaptive mechanisms mainly involved the appearance of protective enzymes that oppose oxygen, such as peroxidases, catalases, and superoxide dismutases, which remove the radical toxins generated by oxygen. Cyanobacteria themselves can be poisoned by the oxygen that they produce. Some cyanobacteria of the genus Phormidium can be found in anaerobic environments. These organisms require other aerobic microorganisms that consume the oxygen that they generate through photosynthesis (Urmeneta \& Navarrete, 2002).

Plants, like cyanobacteria, have PSII and thus perform oxygenic photosynthesis. In fact, according to the theory of symbiogenesis, which is increasingly supported by scientific evidence, chloroplasts, the organelles responsible for photosynthesis, are nothing more than endosymbiotic cyanobacteria (Margulis, 1981; Margulis \& Bermudes, 1985; Sapp et al., 2002). The pigment responsible for the capture of sunlight, chlorophyll, is identical to the cyanobacterial pigment. Therefore, we could conclude that the origin of photosynthesis, this 
vital metabolism for the maintenance of life on our planet, is exclusively prokaryotic.

\section{O Showing Microbial Populations: Winogradsky Columns}

Winogradsky columns can be used to show visitors phototrophic oxygenic and anoxygenic microorganisms. These columns owe their name to the Russian microbiologist Sergei Nicholaevitch Winogradsky (18561953) (Waksman, 1946, 1953; Thornton, 1953), who designed them in 1880 to study the microorganisms of soil (Winogradsky, 1887, 1889, 1890). The column is a miniature ecosystem, normally anaerobic, that includes all the prokaryotes that intervene in the nutrient cycle.

Two glass columns with a height of $1.5 \mathrm{~m}$ and a diameter of $20 \mathrm{~cm}$, with highly resistant supports, were made following the plan shown in Figure 1. The biological material required to build the ecosystem was collected from the Ebro Delta (Tarragona, Spain), in the sampling zone in which microbial mats are studied (Urmeneta, 1995).

The aerobic column was half filled with sand from a beach. Next, it was filled with sea water. To favor the development of microbial communities, the column was inoculated with $10 \mathrm{~mL}$ of a culture of marine cyanobacteria obtained from microbial mats in the Ebro Delta. Finally, $7.5 \mathrm{~g}$ of potassium nitrate and $0.2 \mathrm{~g}$ of monosodium hydrogenophosphate were added. By contrast, the anaerobic column was half filled with black sediment collected from the lower section of the microbial mats. Several $1-\mathrm{cm}^{2}$ pieces of filter paper, $30 \mathrm{~g}$ of Luria-Bertani broth medium, $20 \mathrm{~g}$ of sodium sulfate, and $4 \mathrm{~g}$ sodium sulfide were added to the sediment. Finally, the column was filled with sea water. For both columns, lighting was provided under a

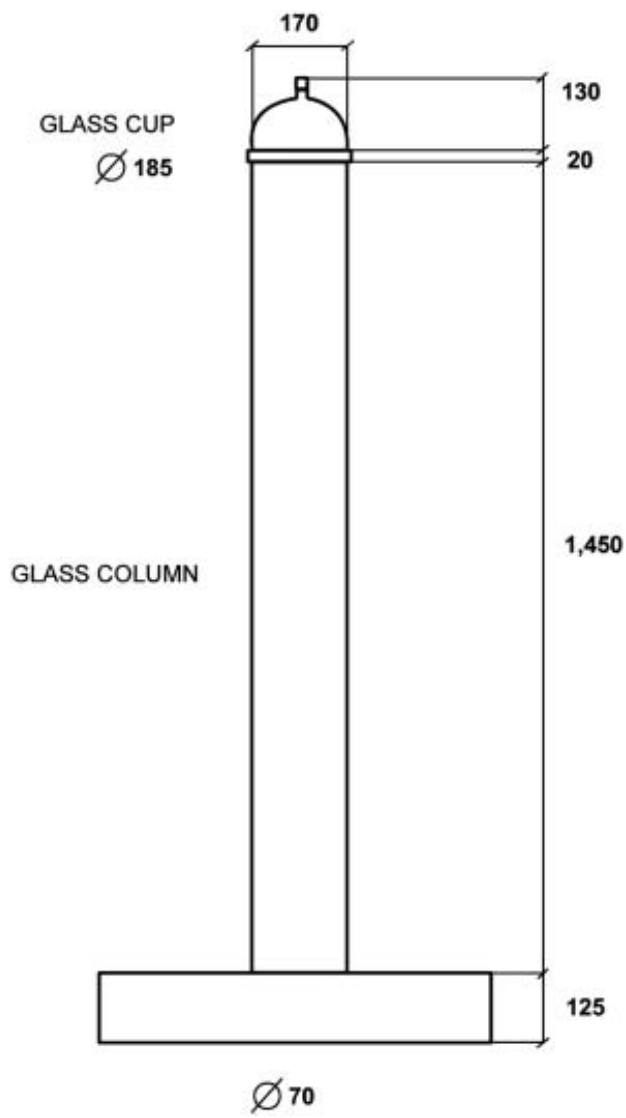

Figure 1. Outline of construction of the glass column. Sizes are in millimeters (figure by Marcel.lí Antúnez). 12-h day/night cycle by two series of six lights (OSRAM Concentra 230V 60W, R $6330^{\circ} 2 \mathrm{ab}$ ) placed at a distance of $3 \mathrm{~m}$, on 1.5 -m-high vertical supports. To monitor the development of the columns, digital photographs were periodically taken from a fixed position.

The two columns show distinct aquatic ecosystems. The first represents a current lake with a column of completely aerobic water where algae and cyanobacteria (all of which are phototrophic oxygenic organisms) predominate. Also, this column demonstrates how oxygen appeared in the atmosphere 2000 million years ago.

These organisms use the energy from light to break water molecules and obtain the electrons from them. This reaction produces a residual product, namely oxygen.

$$
2 \mathrm{H}_{2} \mathrm{O}+\text { light } \Rightarrow 4 \mathrm{H}^{+}+4 \mathrm{e}^{-}+\mathrm{O}_{2}
$$

The second column represents a lake of the Archaean Eon (3500 million years ago) and holds an anaerobic community predominated by purple sulfur phototrophic bacteria (Chromatium sp., Thiocapsa sp.) and green sulfur bacteria (Chlorobium sp.). These microorganisms use light energy to break sulfide molecules, thereby obtaining electrons (Pfennig, 1990; Trüper, 1990). Sulfur is produced during this process.

$$
\mathrm{H}_{2} \mathrm{~S}+\text { light } \Rightarrow 2 \mathrm{H}^{+}+2 \mathrm{e}^{-}+\mathrm{S}
$$

The two Winogradsky columns were assembled in May 2003. The microbial communities developed rapidly. In the first week, microbial growth was already visible in both columns, although growth was not generalized until a month later. The water in the anaerobic column turned an intense red in the first week. After 2 to 3 months, the water was green and the sediment showed several red, pink, green, and white areas (Figure 2). Two months later,

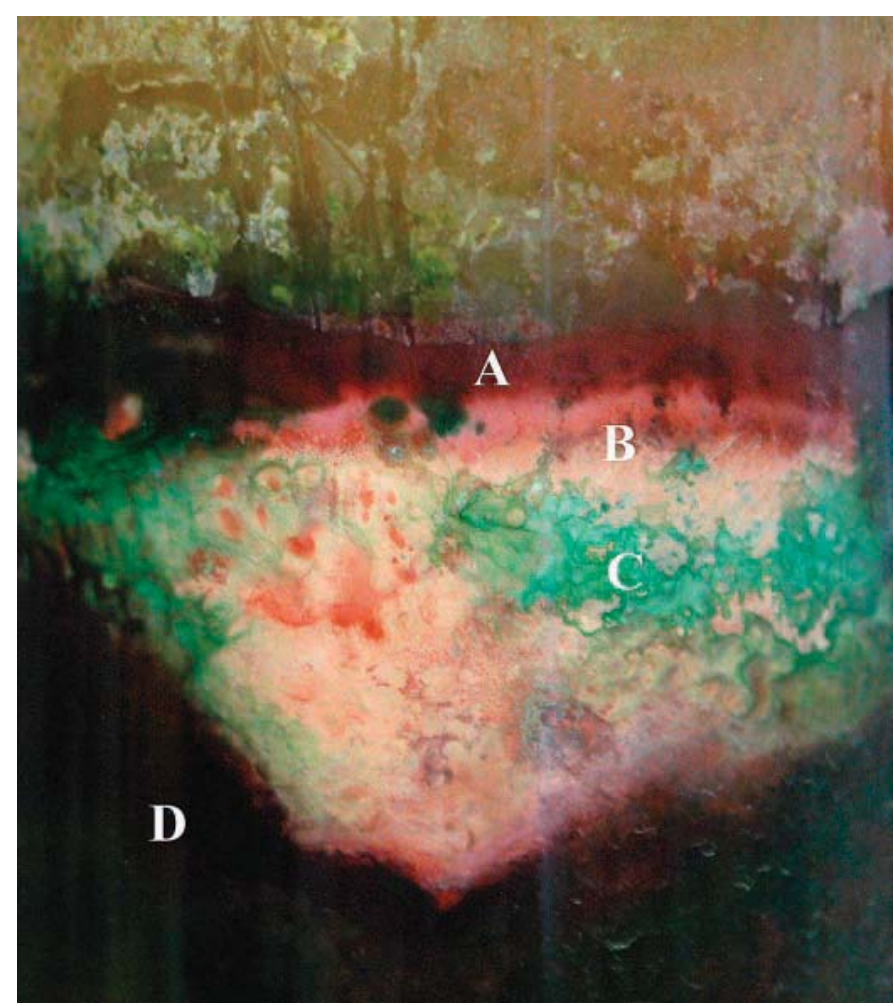

Figure 2. Detail of the anaerobic Winogradsky column, showing the different microbial populations as spots of different colors. Red (A) and pink (B) purple sulfur bacteria; (C) green sulfur bacteria; and black (D) sulfate-reducing bacteria. 
the sediment showed more intense and well-delimited red and pink zones. By contrast, microbial growth developed slowly in the aerobic column and no growth was observed in the first few days. After 2 to 3 months, the water was still clear but sediment showed extensive green patches. Two months later, all the sediment and the entire water column were colonized. After 7 or 8 months, the communities in both columns were stable.

When observing the columns, the spectator does not see individual microorganisms but populations formed by thousands of millions of them. These appear as bright patches of distinct color, depending on the type of pigment they have. Given the dynamic nature of the communities in the columns, the onlooker is likely to find that the columns change from one visit to the next. Populations of microorganisms are evolving constantly, thus balancing the ecosystem. The columns present microorganisms in a macroscopic form, visually communicating their importance to the visitor. Observation of the anaerobic column allows the spectator to view a form of life (without oxygen) that may be totally unknown.

In addition to the Winogradsky columns, the First Metabolisms exhibit includes other elements that contribute to visitors' understanding. Two original drawings depict the diversity of a microbial phototrophic community, like that of Cisó Lagoon. At the same time, each column is described in an audiovisual presentation. It explains the differences between the anaerobic column, which corresponds to a model of primitive Earth (3500 million years ago), and the aerobic one, which represents contemporary conditions. By drawing the visitor's attention to the changes in color, this presentation also shows how the proportions of microbial communities in the columns have changed over time. It goes on to explain that such changes reflect the dynamic nature of microbial ecosystems. Afterwards, the visitor zooms in on a specific patch of color until the species occupying that space become visible. And finally, several images and interactive diagrams describe the metabolism of each of the species in the columns. These diagrams emphasize the enormous metabolic diversity among the microorganisms and their crucial contribution to the development of life on Earth, particularly with regards to the recycling of matter and the use of highly varied energies.

Thus, while contemplating the columns, the visitor is guided through a summary of the history of life on Earth.

\section{O Showing Microbial Populations: Cyanobacteria}

To observe oxygen production by cyanobacteria, several strains were isolated from the microbial mats of the Ebro delta and cultured in 150-mm-diameter Petri dishes provided with liquid marine mineral medium (MN). The plates were kept in an incubation chamber at $19-23^{\circ} \mathrm{C}$ under a 12 -h day/night cycle. Light was provided from a mixture of fluorescent gro-lux-type tubes and cold white light (all $18 \mathrm{~W}$ and in a 1:1 proportion, refs. F18W/GRO and F18W/133-ST of the Sylvania catalogue). The water level was controlled weekly, and distilled water was added when necessary.

The aim of this initiative was to show the photosynthetic activity of the cultures by observing the appearance of oxygen bubbles. Cultures of filamentous slime cyanobacteria give rise to considerable bubble formation. Once bubbles have formed, slime favors their maintenance for extensive periods (Figure 3). An exhibition table covered by a glass lid that can be opened was designed and assembled. The main problem in the design of this module was how to prevent condensation on plate lids and the table lid. This problem was

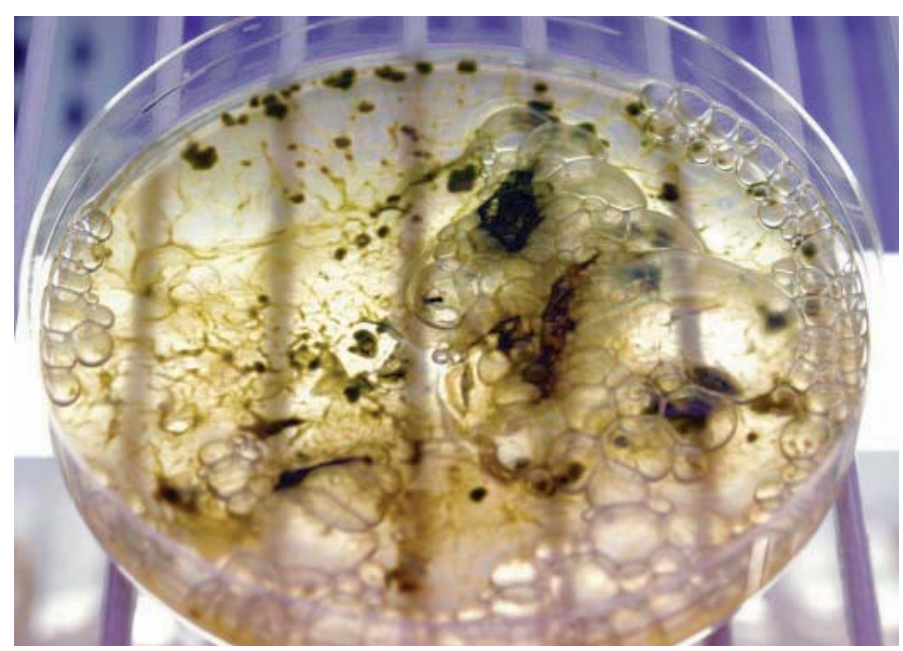

Figure 3. Petri dish with a culture of cyanobacteria that presents oxygen bubbles.

minimized by maintaining constant conditions of humidity and temperature. Given the heat generated by the lighting system, a refrigeration system is recommended.

\section{O Interpretations \& Conclusions}

We have described one approach to the presentation of microorganisms in a science museum in such a way that allows the visitor to appreciate their role in the evolution of our planet. Living organisms are exhibited using a combination of scientific, artistic, and museological knowledge. Falk et al. (2007) contend that museum visits provide an amenable experience in which a wide range of audiences can acquire general and scientific knowledge. In this particular case, does the initiative adopted at CosmoCaixa Barcelona motivate the public to learn about and take an interest in microorganisms? To answer this question, it is sufficient to observe people's reactions "in situ." Visitors stop to contemplate the columns in the way one might contemplate a sculpture. However, unlike static sculptures, these columns allow visitors to interact with the exhibit itself. They touch and observe the columns closely, walk around them, and concentrate on the audiovisual presentations and the scientific drawings. In the former, they compare the distinct origin of the columns, the microorganisms inside, and, in addition, the metabolism of each of the species in the columns. By contrast, the drawings allow visitors to ponder the diversity of forms of these microorganisms. In case of school visits, teachers invite their pupils to make their own observations, adapting the explanations to the different ages (A. Duró pers. obs: museological experience).

For university students, the observation of Winogradsky's columns also contributes to a greater understanding of microbial communities. Students in their final year of biology, all with a solid knowledge of microbiology, are surprised to observe the Winogradsky columns, used in the study of microbial ecology. After understanding the functioning of ecosystems, they show great interest in observing the microorganisms that form the diversity of colors under a microscope. Students say that they would never have imagined that such microbial diversity could be present in a single drop of water. After completing their work with microscopes, they ask for further information on how to set up a column of this kind at home so that they can observe the spectacular changes (J. Urmeneta pers. obs.: educational experience). 
Microorganisms were crucial in the appearance and maintenance of life on our planet. Museums and exhibitions have frequently not given microorganisms the merit they deserve. However, times are changing, and the public is being made aware of the importance of these minute life forms that accompany us in our daily lives. We consider that information gathered from questionnaires (before and after visiting the museum) and direct observations of visitors will enhance our knowledge of the interaction of the public with modules and the learning acquired about the microbial world (Prats et al., 1988; Martínez Vilalta et al., 2003).

\section{Acknowledgments}

We thank the Parc Natural del Delta de l'Ebre of the Autonomous Government of Catalonia (Generalitat de Catalunya) for permission to enter the protected area of La Banya and collect samples there. We are grateful to Marcel-lí Antúnez (an artist) for the design and construction of glass columns and the equipment with the lighting system for the cyanobacteria, and to Prof. Ricardo Guerrero for useful suggestions and discussion during the preparation of this article.

\section{Educational Resources on the Web}

http://www.exploratorium.edu/theworld/glow/grow.html http://serc.carleton.edu/microbelife/topics/special_collections/ winogradsky.html

\section{References}

Benlloch, M. \& Williams, V.N. (1998). Influencia educativa de los padres en una visita al museo de la ciencia: actividad compartida entre padres e hijos frente a un módulo. Enseñanza de las Ciencias, 16, 451-460.

Falk, J.H., Storksdieck, M. \& Dierking, L.D. (2007). Investigating public science interest and understanding: evidence for the importance of free-choice learning. Public Understanding of Science, 16, 455-469.

Guisasola, J. \& Morentin, M. (2007). Qué papel tienen las visitas escolares a los museos de ciencias en el aprendizaje de las ciencias? Una revisión de las investigaciones. Enseñanza de las Ciencias, 25, 401-414.

Hofstein, R. \& Rosenfeld, S. (1996). Bridģing the gap between formal and informal science learning. Studies in Science Education, 28, 87-112.

Lechevalier, H.A. \& Solotorovsky, M. (1974). Three Centuries of Microbiology. New York, NY: Dover.

Lucas, A.M. (1983). Scientific literacy and informal learning. Studies in Science Education, 10, 1-36.

Marogulis, L. (1981). Symbiosis in Cell Evolution: Life and its Environment on the Early Earth. San Francisco, CA: W.H. Freeman.

Marogulis, L. \& Bermudes, D. (1985). Symbiosis as a mechanism of evolution: status of cell symbiosis theory. Symbiosis, 1, 101-124.

Martínez Vilalta, J., Sauret, M., Duró, A. \& Piñol, J. (2003). Make your own transpiring tree. Journal of Biological Education, 37, 1-4.
Maury, J.-P. (1994). Le Palais de la Découverte. Évreux, France: Ed. Gallimard, Imprimerie Kapp Lahure Jombart.

Oppenheimer, F. (1968). A rationale for a science museum. Curator, 11, 206-209.

Pedretti, E. (2004). Perspectives on learning through research on critical issues-based science center exhibitions. Science Education, 88, 34-47.

Pfenniģ, N. (1990). Ecoloģy of phototrophic purple and green sulfur bacteria. In H. G. Schlegel and B. Bowien (Eds.), Autotrophic Bacteria, pp. 97-116. Berlin, Germany: Springer-Verlag.

Prats, C., Flos, J., Piqué, J., Carrau, M.J. \& Duró, A. (1988). Anàlisi d'una exposició itinerant: “L’Ecologia.” Investiǵació Museística, no. 3. Barcelona, Spain: Ajuntament de Barcelona.

Rennie, L.J. \& McClafferty, T.P. (1996). Science centres and science learning. Studies in Science Education, 27, 53-98.

Salmi, H. (2003). Science centres as learning laboratories: experiences of Heureka, the Finnish Science Centre. International Journal of Technology Management, 25, 460-476.

Sapp, J., Carrapiço, F. \& Zolotonosov, M. (2002). Symbiogenesis: the hidden face of Constantin Merezhkowsky. History and Philosophy of the Life Sciences, 24(3-4), 413-440.

Stanier, R.Y. (1951). The life-work of a founder of bacteriology. Quarterly Review of Biology, 26, 35-37.

Thornton, H.G. (1953). Sergei Nicholaevitch Winogradsky, 1856-1953. [Obituary.] Notices of Fellows of the Royal Society, 8, 635-644.

Trüper, H.G. (1990). Physiology and biochemistry of phototrophic bacteria. In H.G. Schlegel and B. Bowien (Eds.), Autotrophic Bacteria, pp. 267-281. Berlin, Germany: Sprinģer-Verlaģ.

Urmeneta, J. (1995). Distribución geográfica y ecofisiología de los tapetes microbianos del Delta del Ebro. Ph.D. dissertation, University of Barcelona, Barcelona, Spain.

Urmeneta, J. \& Navarrete, A. (2002). Hay alguien ahí? Colección Quintaesencia. Las respuestas de la Ciencia. Barcelona, Spain: Ed Océano.

Waksman, S.A. (1946). Sergei Nikolaevitch Winogradsky, September 1, 1856-August 31, 1946. The story of a great bacteriologist. Soil Science, 62, 197-226.

Waksman, S.A. (1953). Serģei N. Winogradsky: His Life and Work. New Brunswick, NJ: Rutogers University Press.

Winogradsky, S. (1887). Concerning sulfur bacteria. In R.N. Doetsch (Ed.), Microbiology: Historical Contributions from 1776 to 1908. [Book published 1960.] New Brunswick, NJ: Rutgers University Press.

Winogradsky, S. (1889). Physiological studies on the sulfur bacteria. In T. Brock (Ed.), Milestones in Microbiology. [Book published 1999.] Washinģton, D.C.: ASM Press.

Winogradsky, S. (1890). The nitrifying organisms. In T. Brock (Ed.), Milestones in Microbiologyy. [Book published 1999.] Washinģton, D.C.: ASM Press.

JORDI URMENETA is Associate Professor of Microbiology at the University of Barcelona, Av. Diagonal, 645 E-08028 Barcelona, Spain; e-mail: jurmeneta@ ub.edu. ALICIA DURÓ is a Postdoctoral Scientist in the Institute of Marine Sciences (ICM-CSIC), Pģ. Marítim de la Barceloneta, 37-39 E-08003 Barcelona, Spain; e-mail:aduro@icm.csic.es. 